\title{
Museums as Hubs for Disaster Recovery and Rebuilding Communities
}

\author{
Isao Hayashi
}

\begin{abstract}
Among many museums throughout Japan that address the subject of disaster, the attention was drawn to the Chuetsu Earthquake Memorial Corridor which is composed of four facilities and three parks. One facility in Nagaoka acts as gateway to the Corridor, another in Ojiya is responsible for disaster prevention education, the one in Kawaguchi aims to reveal the connections born between people, and the one in Yamakoshi recounts the history, culture, and reconstruction of the village. Memorial parks were established in Myoken as a "park for prayer," in Kogomo as a "park for remembering," and at the Epicenter as a "park for beginnings." The author thus introduced the significance of involving the local people in the planning process and management of facilities that represent and reflect their own experiences.
\end{abstract}

\section{Introduction}

Disaster-induced deaths in the Asian-Pacific region account for more than half of the total number of victims in the world (Fig. 1). Needless to say, most countries, regions, and communities have been making efforts to reduce the number of deaths caused by all kinds of disaster. At the same time, recently, working out recovery strategies from a disaster in advance is one of the new focal issues in the field of disaster studies.

After the occurrence of the Great East Japan Earthquake, in the "Towards Reconstruction" presented by the Reconstruction Design Council at the end of June 2011, the first item listed among the Seven Principles for the Reconstruction Framework stated that "there is no other starting point for the path to recovery than to remember and honor the many lives that have been lost. Accordingly, we shall record the disaster for eternity, including through the creation of memorial forests and monuments, and we shall have the disaster scientifically analyzed by a broad range of scholars to draw lessons that will be shared with the world and passed down to posterity." Moreover, in order for this to be incorporated, the establishment

\footnotetext{
I. Hayashi $(\bowtie)$

National Museum of Ethnology, Senri Expo Park, Suita, Osaka 565-8511, Japan

e-mail: isaki@idc.minpaku.ac.jp
} 


\section{More and increasing disasters in Asia}

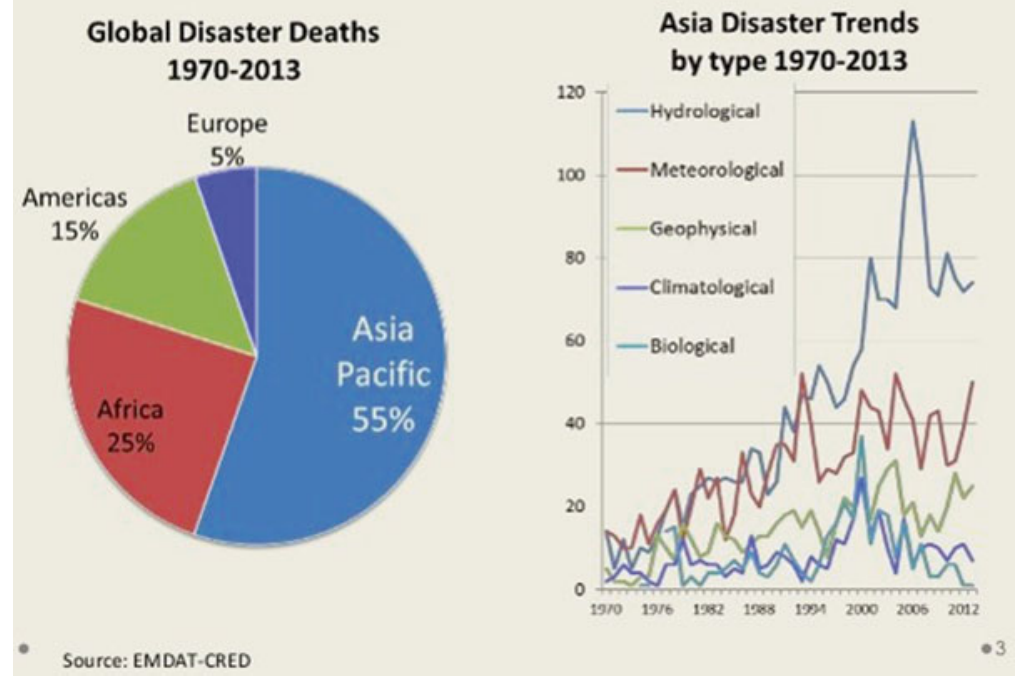

Fig. 1 Global disaster deaths and Asia disaster trends for 1970-2013 (Source: Thomas (2014))

of facilities, such as memorial parks, monuments, and severely damaged buildings, for conveying experiences and lessons learned from the disaster in the future was planned as part of the reconstruction plans of the municipalities and prefectures affected by the disaster, and some of those localities are already in the process of implementing these plans. Museums have been recognized as an important medium for disaster risk reduction by transferring and sharing past disaster experiences.

There are many museums throughout Japan that address the subject of disasters. The Disaster Reduction and Human Renovation Institution in Kobe is a facility introducing the destruction and activities in the rescue and recovery process of the 1995 Great Hanshin-Awaji Earthquake. There are about 500,000 visitors a year, and it is not only an exhibition hall, but also a research institution related to disasters and disaster prevention that holds training programs mainly targeting government officials in charge of disaster prevention. The Inamura-no-Hi no Yakata (Fire of Rice Sheaves Mansion), located in Yuasa Town of Wakayama Prefecture, is a facility that encompasses the neighboring Tsunami Educational Center and in which the old house of Goryou Hamaguchi, the hero in the story of the "Fire of Rice Sheaves," serves as a memorial hall. The Mt. Unzen Disaster Memorial Hall in the Shimabara Peninsula of Nagasaki Prefecture serves as a facility related to volcanoes. These facilities are large-scale, specialized museums related to disasters, and not only do they have exhibitions on past disasters, they are also places where people can learn about measures against potential future disasters, namely disaster prevention and reduction. There are also many other facilities that have adopted the subject of 
disasters as part of their exhibitions. The common thread is that these facilities have the goal not only of introducing past disasters, but also of putting lessons learned from disasters to use for future disaster prevention and reduction.

The Chuetsu Earthquake Memorial Corridor is unique and it deserves attention. In addition to preserving and disseminating memories and records of the disaster, passing on lessons learned from experiencing the disaster, and cultivating awareness of disaster prevention and reduction, the Corridor had local people involved in the establishment and management of the facilities, it is positioned to assist in rebuilding the lives of those people, and aids in reviving and developing communities located in intermediary areas between plains and mountains severely damaged by the earthquake. I will introduce here the significance of involving the local people in the process and management of the facilities that represent and reflect their own experiences.

\section{Chuetsu Earthquake Memorial Corridor}

\subsection{Chuetsu Earthquake}

The Niigata Chuetsu Earthquake, which had its epicenter in the Chuetsu region of Niigata Prefecture, occurred at 5:56 pm on October 23rd, 2004. A distinctive characteristic that can be pointed out about this earthquake was that it brought about great destruction in mountainous areas. In particular, following the earthquake, mountains crumbled, roads became blocked, and 61 villages became isolated. The evacuation of all of the villagers from the former Yamakoshi Village was publicized as a representative example of this. In the mountainous areas where there was great destruction, the earthquake served as an impetus for many people to leave the region, and this further spurred depopulation and aging of the population, which had been worsening even before the earthquake. Therefore, an issue central to reconstruction was the matter of achieving sustainability in mountainous areas and, as a pillar of reconstruction, Niigata Prefecture set out to "obtain new sustainability that is full of vitality" for the revitalization phase.

\subsection{Outline of the Chuetsu Earthquake Memorial Corridor}

The Chuetsu Earthquake Memorial Corridor aims to prevent experience of the disaster from fading as time goes by, to the extent possible, leaving sites affected by the disaster as they are. For the corridor facilities, four facilities and three parks were established as places that convey memories of the earthquake, and act as bases for the collection and use of earthquake archives. 


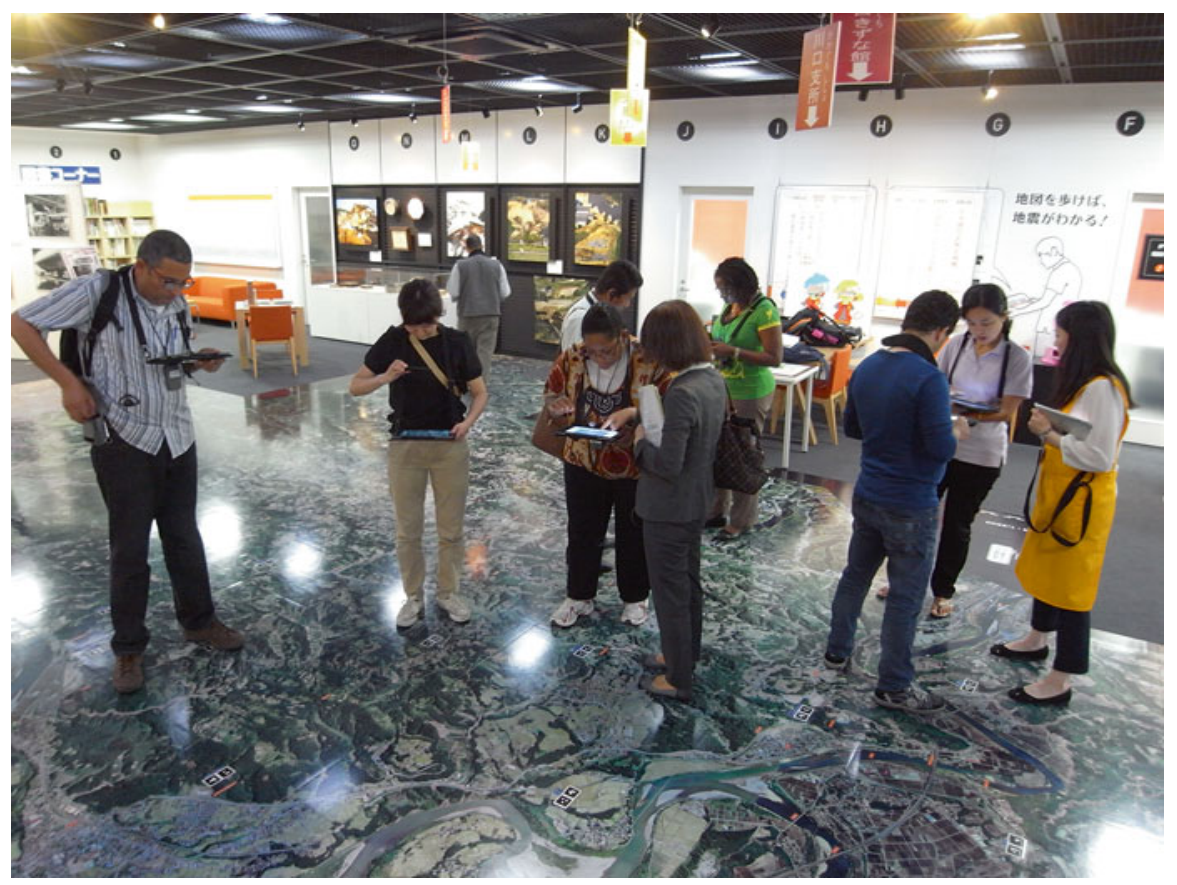

Fig. 2 Nagaoka Earthquake Disaster Archive Center - Kiokumirai (Memories for the Future)

Each of the four base facilities has its own distinctive characteristics. The Nagaoka Earthquake Disaster Archive Center-Kiokumirai (Memories for the Future) (Fig. 2) acts as the gateway to the Chuetsu Earthquake Memorial Corridor, and it is positioned as the core facility of the corridor. It is set up such that people can learn about the earthquake disaster in general here, and learn more detailed information at the other facilities. The Ojiya Earthquake Disaster MuseumSonaekan (Preparedness) (Fig. 3) is in charge of disaster prevention education. This facility conveys lessons learned from the experience of the earthquake in an easyto-understand manner, and with the aim of putting those lessons to use as customary measures, it divides post-disaster life into the four phases of $3 \mathrm{~h}$ post-disaster, 3 days post-disaster, 3 months post-disaster, and 3 years post-disaster, and shows the necessary measures to be taken so that they can be understood in terms of each phase. The Kizuna (Bonds/Ties) Center of Kawaguchi (Fig. 4) plays the part of revealing connections that were born between people (between neighbors, between residents and outsiders, etc.) as a result of the disaster. It not only focuses on past connections that were made at the time of the earthquake, but also relationships that are progressively continuing to develop. The Yamakoshi Restoration Exchange CenterOrataru (My/Our Place) (Fig. 5) plays the part of recounting the path of the history, culture, and reconstruction of the village. While talking about life in the village, voices of the local people recount the path they took to return to Yamakoshi and to 


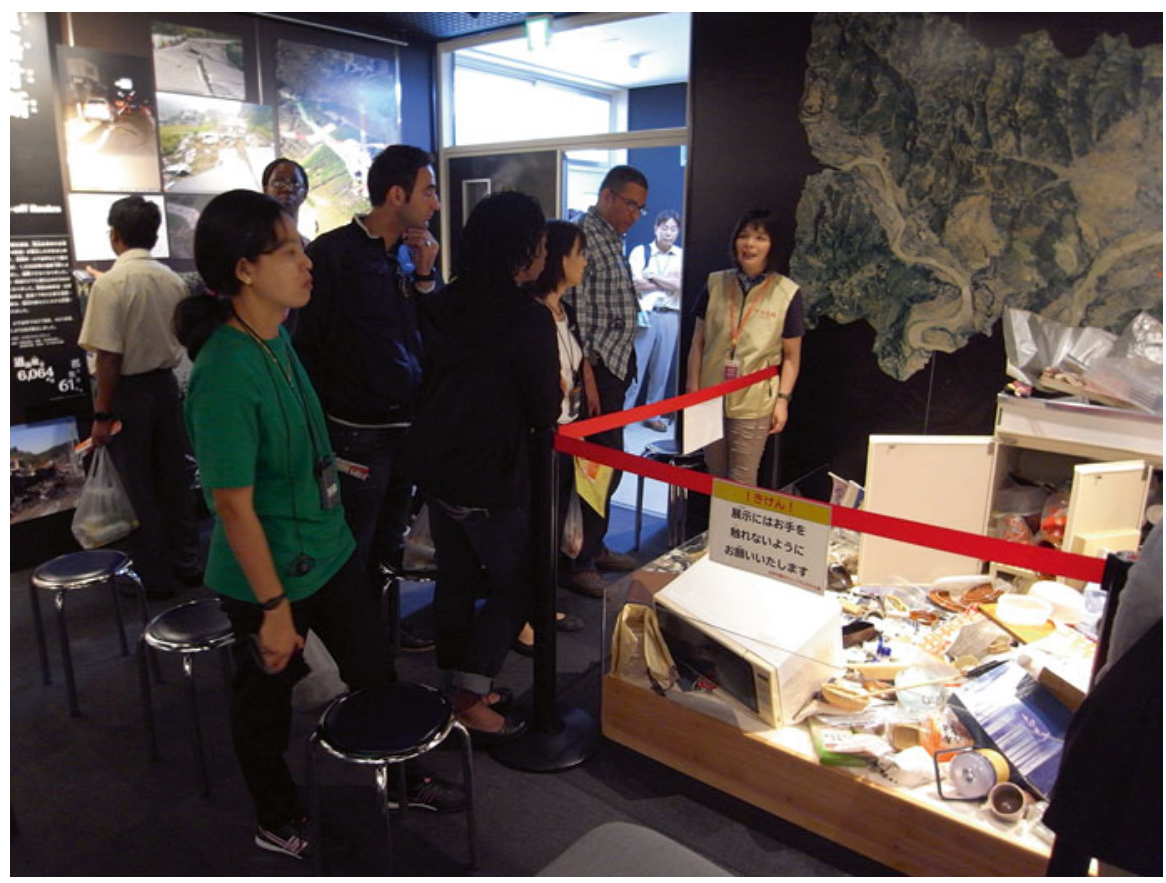

Fig. 3 Ojiya Earthquake Disaster Museum - Sonaekan (Preparedness)

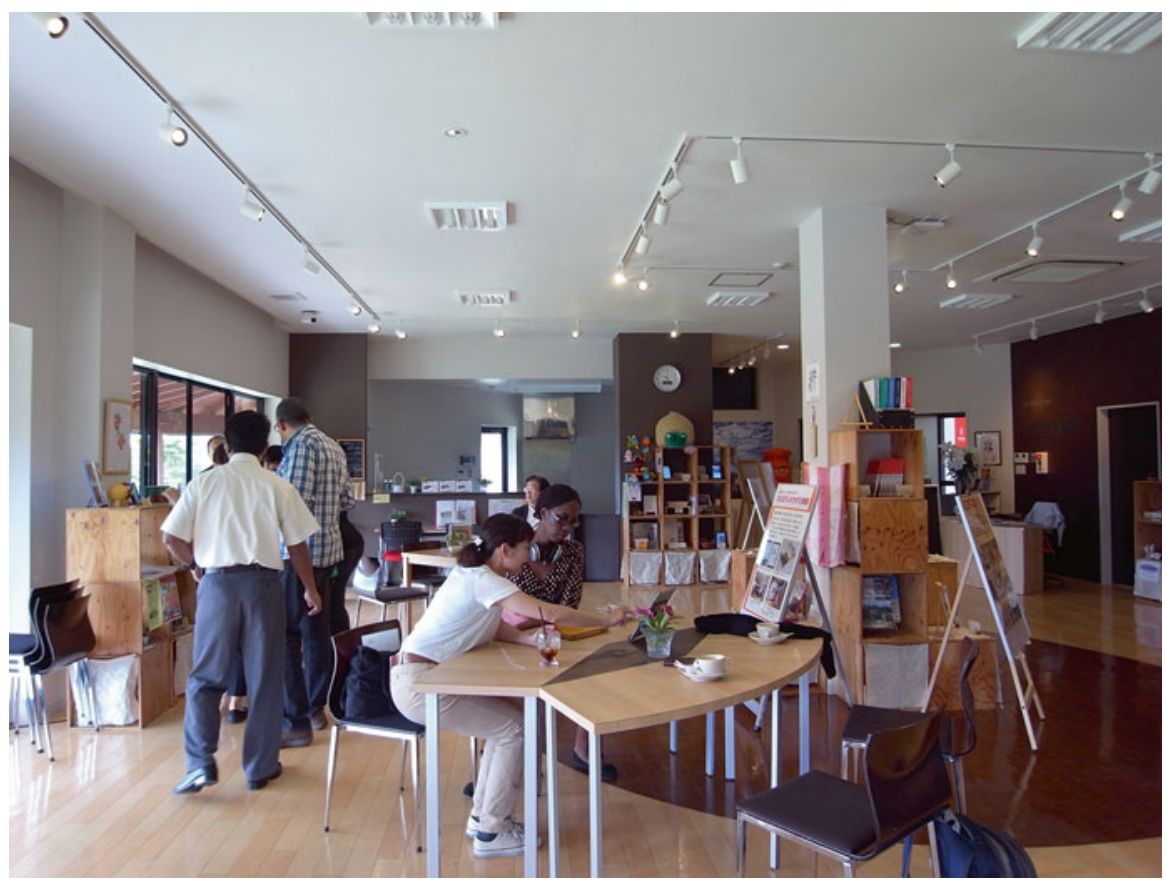

Fig. 4 Kizuna (Bonds/Ties) Center of Kawaguchi 


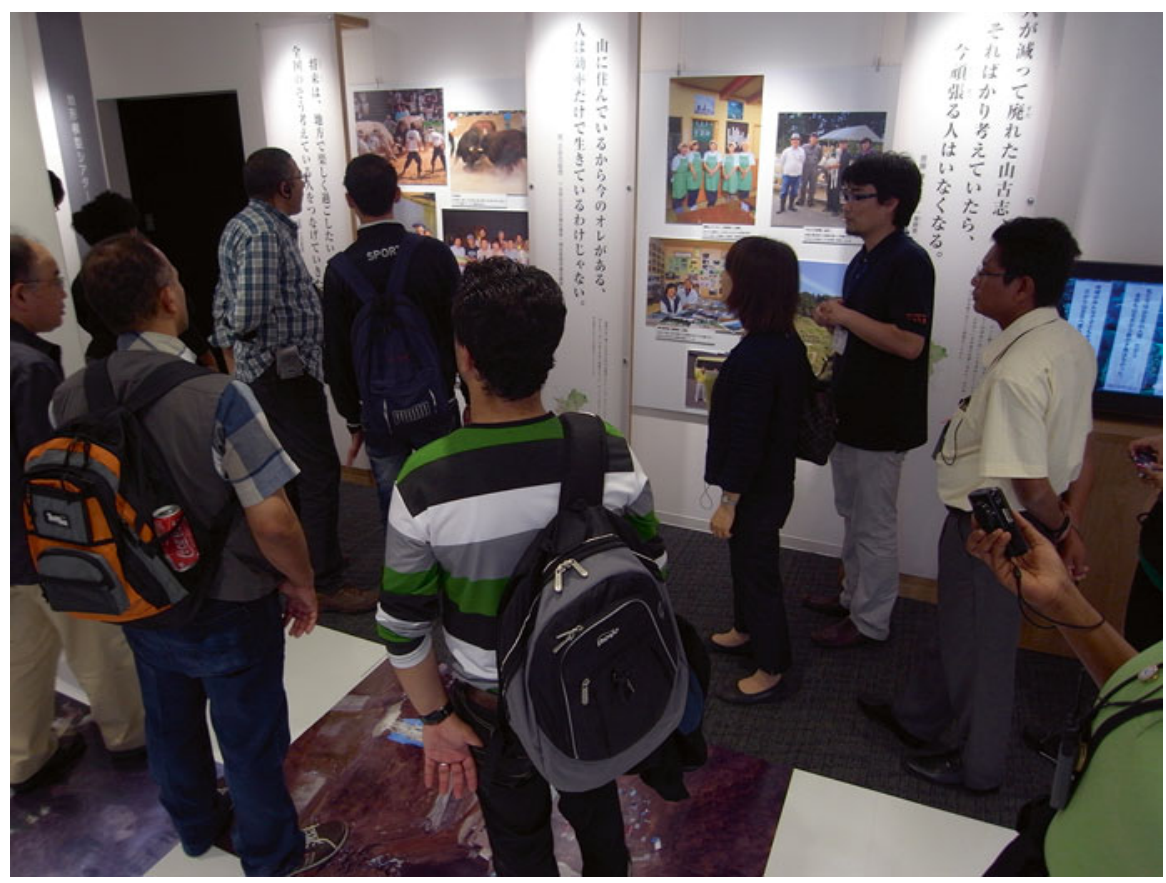

Fig. 5 Yamakoshi Restoration Exchange Center-Orataru (My/Our Place)

revive their hometown, even after being subjected to the extensive destruction of the earthquake.

The three memorial parks are located in places representative of the earthquake. Myoken Earthquake Memorial Park (Fig. 6) was established as a "park for prayer" located near a disaster site where several cars were engulfed in a large-scale landslide. Every year on October 23rd, many flowers are offered to the departed on a flower alter. Kogomo Memorial Park (Fig. 7) was established as a "park for remembering" located near the site of a village that was submerged by a river channel blockage due to the biggest landslide of the Chuetsu Earthquake. The submerged houses still remain as they were at the time of the destruction. The local residents there established and operate an exchange facility called Satomian, where they currently sell local products, such as vegetables, to tourists while they discuss aspects of the disaster and lessons learned. The Epicenter of the Chuetsu Earthquake Memorial Park (Fig. 8) was established as a "park for beginnings" located at the site of the epicenter of the Chuetsu Earthquake. As an event to mark the first anniversary of the earthquake, local residents and other participants, including myself, found the site of the earthquake epicenter using GPS technology. It was located in the center of a terraced rice field. 


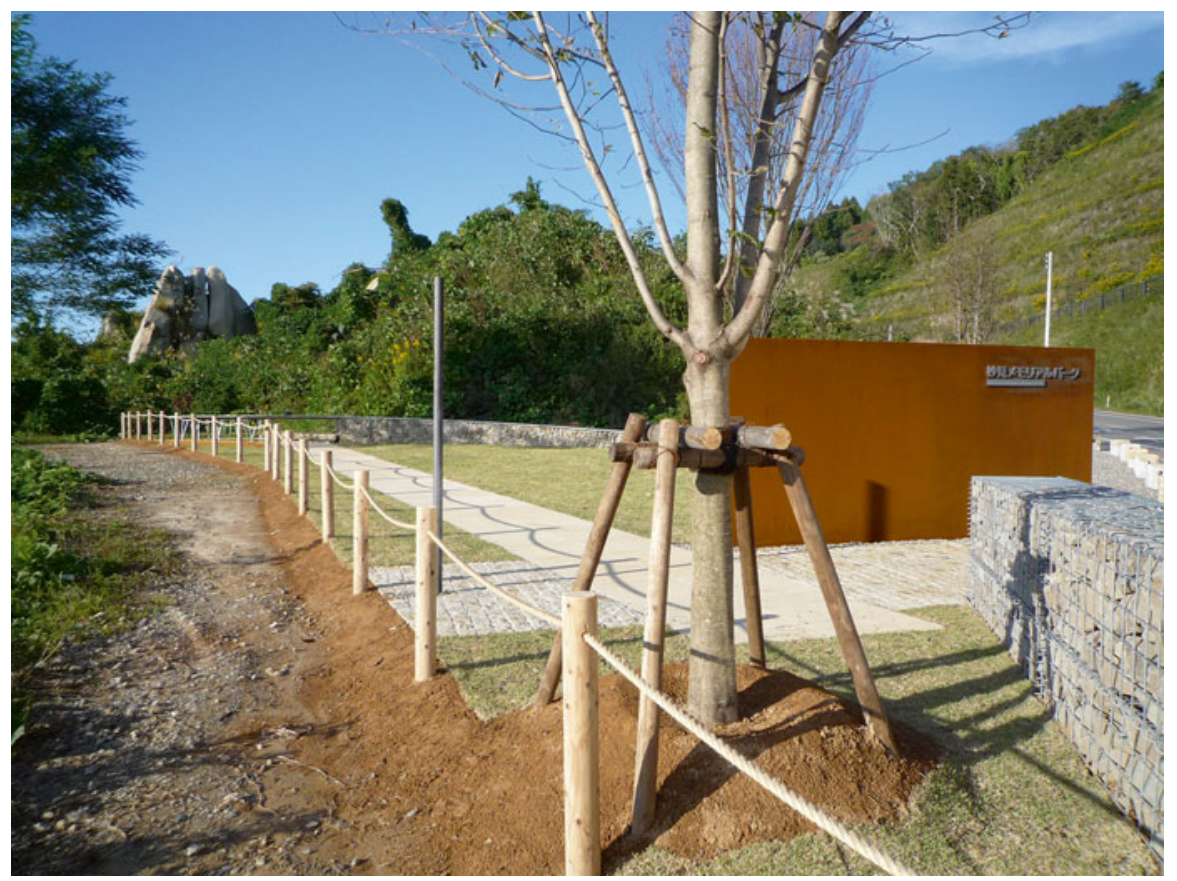

Fig. 6 Myoken Earthquake Memorial Park

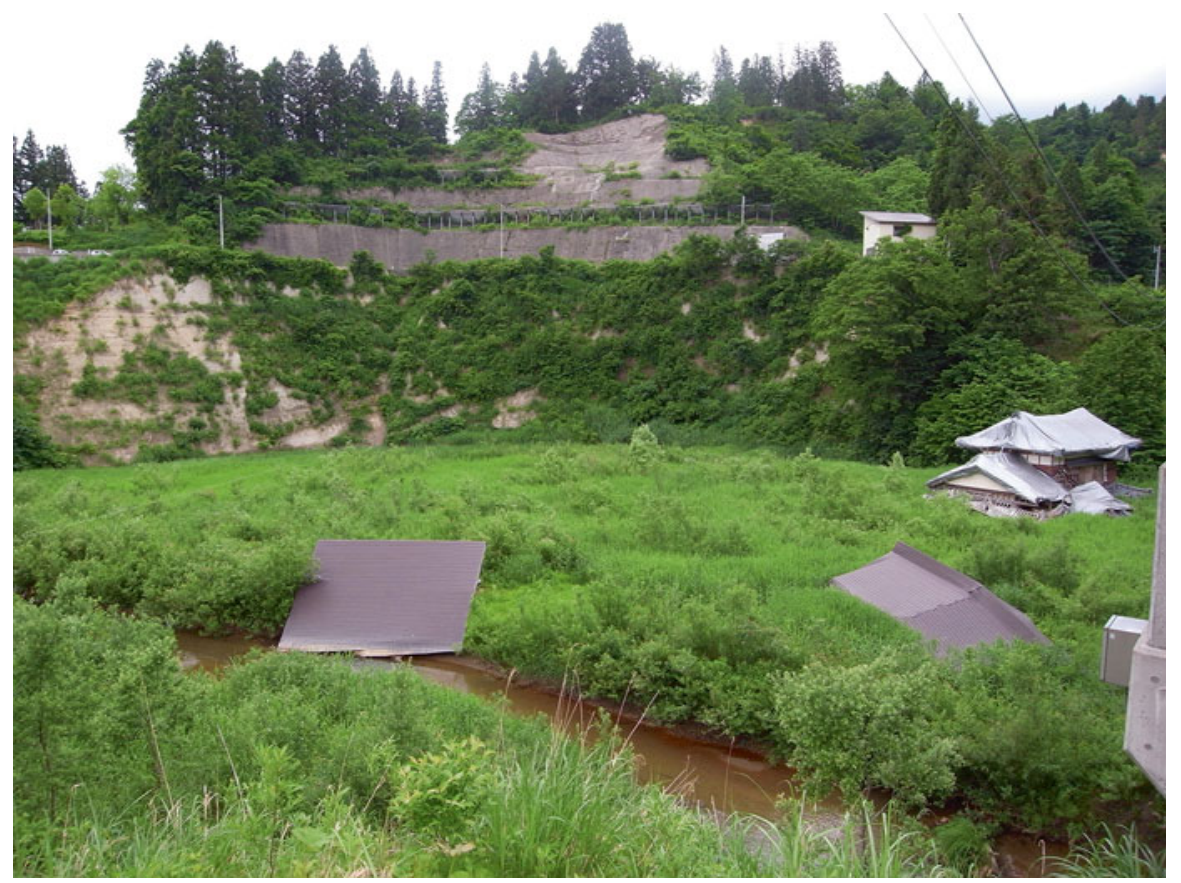

Fig. 7 Kogomo Memorial Park 


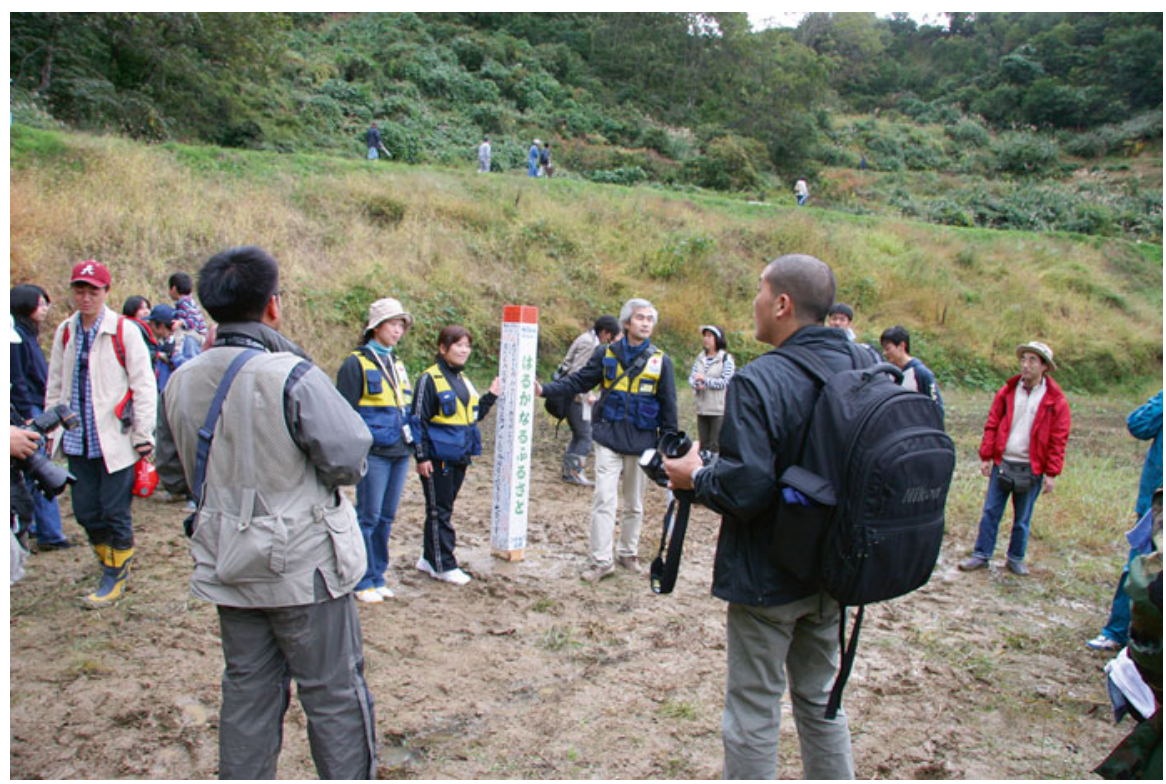

Fig. 8 Epicenter of the Chuetsu Earthquake Memorial Park

\subsection{Resident-Led Initiatives}

Yamakoshi's residents conceived of the Yamakoshi Restoration Exchange CenterOrataru. As the name indicates, the residents actively take part in the management of the Center's exhibition facilities. An NPO founded by Yamakoshi's residents, NPO Chuetsu Disaster Prevention Frontier, is commissioned to manage the facility, and they not only give tours of the building but they also foster storytelling guides who tour all of Yamakoshi, as they convey the story of their earthquake experience and lessons learned. Management of the Kizuna Center of Kawaguchi is also commissioned to an NPO founded by Kawaguchi's residents, the Life Support Echigo-Kawaguchi. At the Ojiya Earthquake Disaster Museum-Sonaekan, storytelling programs, lectures, etc. are carried out through collaboration with an NPO founded by Ojiya's residents, NPO Disaster Prevention Support Ojiya. In this manner, the Chuetsu Earthquake Memorial Corridor functions to collect and disseminate memories of the Chuetsu Earthquake, and local residents are actively involved with its management.

\section{Background to the Establishment of the Facilities}

There are many museums in which citizens carry out volunteer activities or museums that are established by a municipality but total or partial management is privately commissioned, i.e., publicly built and privately operated museums. One significant 
distinctive characteristic of the Chuetsu Earthquake Memorial Corridor facilities is that from the stage at which the establishment of the facilities was under consideration, places were secured where local residents could share their options, and residents have been actively participating in the management of the facilities since their opening.

A distinctive characteristic of the Niigata Chuetsu Earthquake was that it hit mountainous areas where depopulation and aging of the population was already worsening. Due to the earthquake, mountains crumbled, sediment blocked roads and became embedded in rice paddies and reservoirs, and in some cases, terraced rice fields and ponds themselves caved in. At one point, 61 different villages were isolated in a state in which it was difficult for relief supplies to be delivered.

The Chuetsu region is an area that is subject to heavy snowfall and is also an area prone to landslides. Despite the harsh environment, Koshihikari-brand rice is produced on the terraced rice fields created on sloped surfaces formed from landslides, and buyers from places such as China, America, and Europe come to the Chuetsu region seeking Japanese colored carp. It is a land that has bred its own unique culture such as bullfighting, fireworks, and Bon festival dances that vary slightly between each village. However, it was feared that the villages in the mountainous regions affected by the earthquake would further decline by becoming uninhabitable and the residents "descending the mountain" to live in urban areas. The existing decline and aging of the population was in fact exacerbated by this earthquake, which is why Niigata Prefecture adopted "obtaining new sustainability that is full of vitality" as one of the pillars in their reconstruction plans.

In mountainous regions where the decline and aging of the population worsened further due to the earthquake, reconstruction was carried out by first rebuilding individual lives (rebuilding houses and restoring farmlands) and then by rebuilding regional communities. In order to rebuild communities, in addition to restoring infrastructure, shrines and community centers that were the foundation of the community were repaired and rebuilt, events aimed at revitalization were held, and plans for autonomous reconstruction were developed and implemented. Furthermore, exchange programs with outside groups were actively carried out, and community businesses were born, such as farm restaurants and inns jointly managed by the community. These initiatives and the Chuetsu Earthquake Memorial Corridor have created a synergistic effect.

\section{Intermediary Organizations and Reconstruction Fund}

Operation and management of the Chuetsu Earthquake Memorial Corridor is being conducted by the Chuetsu Organization for a Safe and Secure Society. This organization is a public interest incorporated association founded in 2006. This association aims to encourage and support activities related to recording and researching the Chuetsu Earthquake Disaster, while utilizing the research results to create a safe and secure society and to promote disaster prevention and safety industries, by taking advantage of a conglomeration of educational and research institutions in the 
Chuetsu region, through the cooperation and participation of various entities (government, educational and research institutions, companies, and individuals). The Niigata Chuetsu Earthquake Reconstruction Fund established in 2005 is being used as the source of funds for developing the facilities. The Reconstruction Fund is retained under a government reconstruction initiative, and was established with the aim of advancing, over the long term and in a flexible manner, aid and self-support for victims and reconstruction countermeasures in affected areas, and reviving the affected areas into attractive localities. The director of the fund is the governor of Niigata Prefecture. The scale of the fund was 300 billion yen, and operating at an interest rate of $2 \%$ per year, would amount to 60 billion yen over 10 years (Fig. 9).

Since the memorial facilities were viewed as something that would contribute to future disaster response by recording and disseminating the life-rebuilding process, a tool for expressing gratitude for the support received from throughout the nation, and something indispensable to the reconstruction of affected areas, the Reconstruction Fund contributed to the development expenses of the memorial facilities.

The Chuetsu Organization for a Safe and Secure Society acted as a coordinator for connecting support groups, such as the Chuetsu Reconstruction Citizens' Council and specialized institutions like libraries, and residents in affected areas, and it is thought that these connections are also being put to use in the management of the memorial facilities. A portion of the collected materials is currently being exhibited in the Memorial Corridor facilities.

\section{Support by Disaster Reconstruction Fund and Intermediary Organizations}

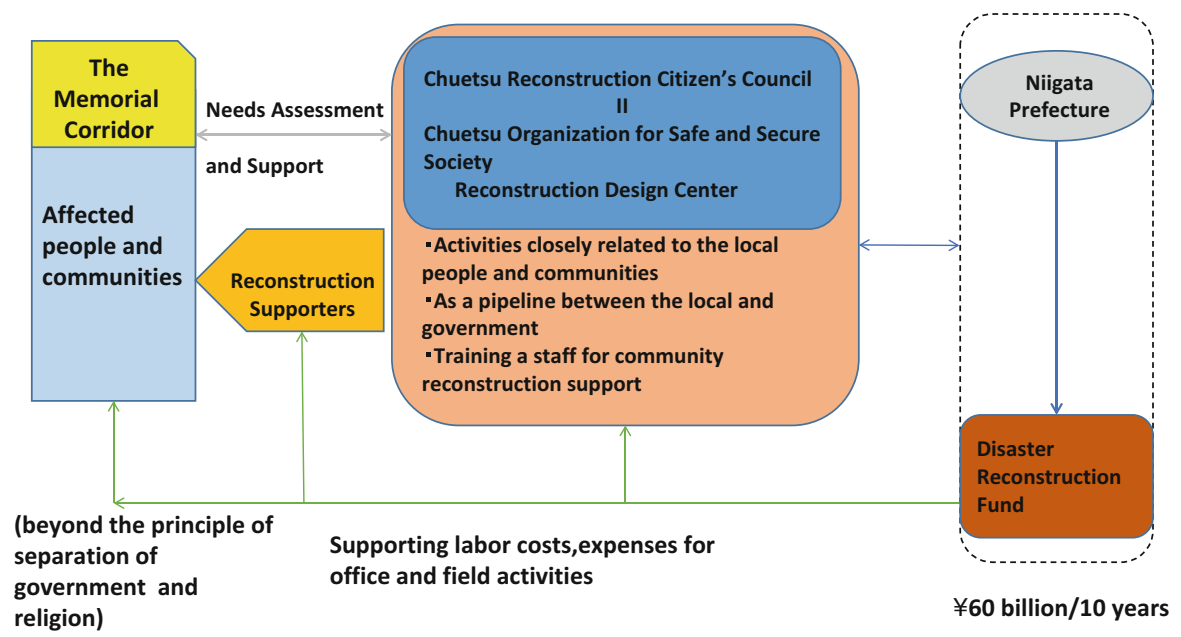

(modified from Aota, Murosaki and Hokugo 2010)

Fig. 9 Support by Disater Reconstructon Fund and Intermediary Organizations (Modified from Aota et al. (2010)) 


\section{Summary}

Interspersing earthquake disaster memorial facilities and the like as a circuit throughout the affected areas, and disseminating information about the earthquake itself and lessons learned, while operating in conjunction with facilities such as roadside rest areas and farm restaurants, lead to the activation of a community in which residents are active players. This serves as a highly suggestive reference case for newly appearing disaster-affected areas, such as those affected by the Great East Japan Earthquake, who are searching for models of post-disaster reconstruction. Moreover, this not only serves as a reference case for reconstruction from disaster but also serves various people, such as administrative officials in charge of regional development, general citizens, and members of volunteer disaster prevention organizations who value connections between neighbors, or even families and small groups of youngsters who want to become acquainted with "mountain life" by interacting with the locals. In response to such needs, the Nagaoka Earthquake Disaster Archive Center-Kiokumirai in the center of Nagaoka City plays the role of introducing facilities and routes in the circuit that can be visited.

Although the Disaster Reduction and Human Renovation Institution in Kobe is a sort of centralized information facility that one can visit to learn a lot about the Great Hanshin-Awaji Earthquake, through circulating multiple facilities, the Chuetsu Earthquake Memorial Corridor introduces the disaster conditions of the regions where each of the facilities is located and the efforts that residents made toward reconstruction, and with this as a backdrop that makes up the region, the history, culture, and issues are also introduced. There are many spots scattered throughout the route circulating those regions that bring visitors into contact with the life of the people and records and memories of the disaster.

The Mt. Unzen Disaster Memorial Hall in the Shimabara Peninsula of Nagasaki Prefecture is also an example constituting a field museum comprising multiple facilities that convey the story of the volcano eruption disaster, such as the Sand Arrestation and Future Museum, the Heisei-shinzan Nature Center, and Onokoba Primary School, which was burned in the pyroclastic flow. However, there is little information about the whole field museum and not many opportunities for exchange with the locals. The Chuetsu Earthquake Memorial Corridor, on the other hand, is a facility where visitors can receive guidance from the Nagaoka Earthquake Disaster Archive Center-Kiokumirai as the gateway, can have the route they visit customized, and can learn about disaster and disaster response in the context of the culture and history of the region through interacting with locals at the destinations they visit.

\section{Notes}

1. The Reconstruction Design Council in Response to the Great East Japan Earthquake, Towards Reconstruction: Hope beyond the Disaster (2011) p. 2.

2. Yamakoshi Village was merged into Nagaoka City Municipality in April 2005.

3. The three pillars of reconstruction are "creative restoration" (restoration phase), "new sustainability full of vitality" (revitalization phase), and "creation of new norms for daily life beyond disaster reconstruction" (development phase). Third Niigata-Chuetsu Earthquake Disaster Reconstruction Plan. 
4. Five Reconstruction Funds were launched before the Great East Japan Earthquake 2011: Unzen-dake Eruption (1991.9 , \109 billion); Hanshin-Awaji Earthquake (1995.9 , 1900 billion); Chuetsu Earthquake (2005.3 , 1305 billion); Noto Peninsula Earthquake (2007.8 , 150 billion); and Chuetsu-Oki Earthquake (2007.10 , \120 billion). Aota et al. (2010), p. 4.

5. In the original estimate, development expenses alone were expected to be approximately 4.1 billion yen. However, the Nagaoka Earthquake Disaster Archive Center is a rented facility and the other three facilities were able to use existing buildings under a free loan, so the total amounted to 2.8 billion yen. Of that, it was decided in a Board of Directors meeting in May 2010 that the fund would contribute 2 billion yen.

Open Access This chapter is distributed under the terms of the Creative Commons AttributionNonCommercial 4.0 International License (http://creativecommons.org/licenses/by-nc/4.0/), which permits any noncommercial use, duplication, adaptation, distribution and reproduction in any medium or format, as long as you give appropriate credit to the original author(s) and the source, provide a link to the Creative Commons license and indicate if changes were made.

The images or other third party material in this chapter are included in the work's Creative Commons license, unless indicated otherwise in the credit line; if such material is not included in the work's Creative Commons license and the respective action is not permitted by statutory regulation, users will need to obtain permission from the license holder to duplicate, adapt or reproduce the material.

\section{References}

Aota, Ryosuke, Murosaki, Yoshiteru, and Hokugo Akitoshi. 2010. Study on the promotion of disaster reconstruction with local initiative, on the basis of the relationship between disaster reconstruction fund and Intermediary Organization. Journal for the Institute of Social Security Society No. 12. http://isss.jp.net/isss-site/wp-content/uploads/2013/08/2009-004_cd1.pdf. Accessed 5 Nov 2015.

The Reconstruction Design Council in Response to the Great East Japan Earthquake. Towards Reconstruction: Hope beyond the Disaster. http://www.cas.go.jp/jp/fukkou/english/pdf/ report20110625.pdf. Accessed 5 Nov 2015.

Thomas, Vinod. 2014. Towards disaster and climate resilience, Presented at the International Scientific Conference on Fisheries and Aquatic Sciences.http://www.slideshare.net/adbevaluation/upv-iloilo-keynote-disaster-and-climate-resilience-21-oct. Accessed 5 Nov 2015. 